\title{
Lexis
}

Journal in English Lexicology

$17 \mid 2021$

Humor, creativity and lexical creation

\section{English Acronyms in Indonesian School Events}

Rio Rini Diah Moehkardi

\section{(2) OpenEdition}

\section{Journals}

Electronic version

URL: https://journals.openedition.org/lexis/5544

DOI: $10.4000 /$ lexis.5544

ISSN: 1951-6215

\section{Publisher}

Université Jean Moulin - Lyon 3

\section{Electronic reference}

Rio Rini Diah Moehkardi, "English Acronyms in Indonesian School Events", Lexis [Online], 17 | 2021, Online since 15 August 2021, connection on 20 August 2021. URL: http://journals.openedition.org/ lexis/5544 ; DOI: https://doi.org/10.4000/lexis.5544

This text was automatically generated on 20 August 2021

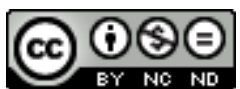

Lexis is licensed under a Creative Commons Attribution-NonCommercial-NoDerivatives 4.0 International License. 


\title{
English Acronyms in Indonesian School Events
}

\author{
Rio Rini Diah Moehkardi
}

This article is a part of my dissertation research on word-formation on English brand names of local products found in Indonesia. I sincerely thank my promotor, Prof. Dr. I Dewa Putu Wijana, my co-promotor, Dr. Tofan Dwi Hardjanto, and my Morphology resource person, Dr. Tri Mastoyo Jati Kesuma. I also thank my research assistants who helped me collect the data in 2018: Adhiesti, Putri, and Ermi. My gratitude also goes to Sydney Allen, the Oberlin Shansi fellow, who proofread my manuscript, and Izzah, who assisted with the nitty-gritty of the paper.

\section{Introduction}

1 Despite the unpredictable nature of their formation and their debatable, unsettled definition and parameters, acronyms - exclusively or including other types of shortenings - have gained popularity among a wide variety of language users, from teenagers using street slang to professional communities. There are various reasons why this type of word formation is universally popular. Among young people, creating words, especially communication expressions, such as acronyms, can help keep their stories exclusive within their peer groups or keep their conversations secret from adults (Mattiello [2008: 37]). They use abbreviations for texting and other internet communication (Cahn [2021]). Among professionals, acronyms, together with initialisms, function to name and categorize their organizations, innovations, committees, systems or programs, diseases, medicines, concepts and events.

2 This naming function, in some way, is practical as it simplifies long and complicated concepts. For example, HIV (initialism) or AIDS (acronym) are easier to remember and pronounce than human immunodeficiency virus or acquired immunodeficiency syndrome. However, at the same time, to a broader public, these names can be confounding, as many acronyms and initialisms are homonyms with entirely different meanings (Cannon [1989], Mattiello [2012], Notosusanto [1979], Wilcox \& McCann [2009]). Acronyms can be problematic due to their dubious nature and dependence on context; 
the output cannot predict the input. Jacobs et al. [2020: 1-2] noted that acronyms may be reinterpreted by a number of possible expansions depending on the context.

In Indonesia, like in English, initialisms and acronyms are also widely used to name institutions, e.g., Lapas « L Lembaga Pemasyarakatan (Correctional Institution); to name historical events, e.g., Malari $\ll$ Malapetaka lima belas Januari (the January $15^{\text {th }}$ Catastrophe); or programs, e.g., KB $\ll<$ Keluarga Berencana (Family Planning).

4 Interestingly, an increasing number of initialisms and acronyms are found in Indonesia where the source phrases are in English. The English words are used to name Indonesian institutions, e.g., SMERU (Social Monitoring and Early Response Unit) Research Institute; programs, e.g., WTE (waste-to-ennergy) facility; and innovations, e.g., GeNose C19 (Gadjah Mada Electronic Nose Covid-19), and ETLE (Electronic Traffic L Law Enforcement). They are correctly and appropriately coined by and for official parties. However, with the growing use of English among the wider population, there is also a growing number of businesses, events, or innovations which use various word-formation processes, such as blending: Foresthree coffee, Storytealing, Anthropocine Week; compounding: Chicken wing KingWing; clipping: Sunmor (Sunday Morning) market, reduplicative: Pizza Pazza, including initialism: WTF (We the Fest, also We the Future) and acronyms: LoL (Land of Leisure) the reinterpretation of LoL (Laughing out Loud). These events or businesses are usually stewarded by young businesspeople or university students.

The striking difference between English and Indonesian acronyms are the length of the letters/splinter allowed to retain, and the position of the retained component in the source phrase.

This article, therefore, attempts to present the phenomena of Indonenglish acronyms, English acronyms coined by Indonesian students in an Indonesian context. It explores how educated, young Indonesian people use English words and adopt English norms to create the acronyms when naming their school events and programs. As acronyms are also a common linguistic phenomenon in Indonesia, it is interesting to observe how cultural and linguistic norms influence Indonesian acronym coiners' English acronyms production, a common phenomenon in a cross-lingual situations. This research, therefore, proposes the following question: Do those who coin acronyms consistently follow English rules of acronym formation? If they apply Indonesian rules, when do they use them? Before exploring my data and findings, the following section discusses the state of acronym production in the context of English and Indonesian shortenings

\section{A brief overview of English and Indonesian acronyms}

7 Although acronym formation in English has been widely discussed, it still relies on unclear or overlapping definitions. Cannon [1989:116] defines "shortening" as a general term to describe initialism, abbreviations, and acronyms - where words are blended and reduced to shorter forms. He further clarifies that initialism is the general term for abbreviations and acronyms. Cannon defines abbreviation as "an item created from one or two first letters of all or most of the 1-5 constituents of an existing item." He defines an acronym as:

An item created from the first letter (infrequently the second and even the third letters) of all or most of the 3-9 constituents of an existing compound. Initial bound forms and free forms prefixed by a bound form may be part of the representation, 
and the resulting shortening is pronounced syllabically according to orthoepic practice. Cannon [1989: 116] the sources, the graphic abbreviation, a sequence of letters, when converted to speech, are spoken with the word abbreviated; for example, Mr. is pronounced /'mIstər/. De Vries [1970] suggests this sub-classification of graphic abbreviation is similar to abbreviations in Indonesian. For example, bhw $\ll$ is spoken bahwa (that) or a.l. $\ll$ is pronounced as its full source phrase antara lain (among others). This definition of abbreviation is also shared by López Rúa [2002], who characterizes abbreviation by its pronunciation following the expanded form of the source word(s), for example, the abbreviated form of Monday, Mon, is pronounced /'mındeI/. Therefore, an abbreviation by this definition is mainly used in written context. In contrast to graphic abbreviation, de Vries [1970] introduces the term 'letter word' for a formation consisting of either initial letters or the non-initials of each word in the source phrase, pronounced either by naming its individual letters or pronounced like a full word.

López Rúa [2002] also suggests the scope of abbreviation and clipping, a shortened form in at least one syllable, lies in their pronunciation. A clipping is pronounced as a new word, defying its original form; for example, flu, the reduced form of influenza is pronounced as /'flu:/. However, following de Vries' classification, such a form in Indonesian is still under the category of abbreviation despite its unexpanded pronunciation, similar to English clipping (de Vries [1970]). For example, pak $<<$ bapak (a term of address to an adult male) or a shortened form of a proper name: No << Soekarno can be pronounced through clipping. However, Quirk et al. [1985: 1580-1584], Plag [2003:160-164], Conti \& Mattiello [2008] and Mattiello [2013:65] define abbreviation as a more general term in which the abbreviated words can be pronounced by naming each letter or by pronouncing the retained letters as a word. The former is called initialism, e.g., UK, HIV; and the latter is an acronym, e.g., laser. Kreidler [2000: 957] suggests acronyms are superordinate, not parallel, to initialisms. He classifies acronyms as (1) alphabetic acronyms (letter naming) whose formation is spelled by its letters (UK) and (2) orthoepic acronyms (letter sounding) whose construction is pronounced like a word (NATO). Furthermore, Kreidler [2000: 958] also classifies alphabetic acronyms as abbreviations.

11

In contrast to Kreidler, López Rúa [2002: 38] considers initialism as the superordinate of alphabetism, e.g., $B B C$, and acronyms e.g., radar; but Mattiello groups acronyms and initialisms under abbreviation [2013: 65]. Stockwell \& Minkova [2001: 7] consider an acronym "a special type of blend" in which the components retained from the source are often larger than just the initial sounds of a source. Their definition of an acronym is in line with that of acronyms in Indonesian. Kridalaksana [1989: 159-178] uses either term: "abbreviation" (abreviasi) or "shortening" (singkatan) to cover the whole shortening word-formation processes in Indonesian, including acronyms. However, Chaer [2008: 236-239] uses the term "acronym" (akronim) to define any wordformations that include shortening. Unlike Moehkardi's previous research [2016] in which she agrees with Kreidler [2000], who suggests that initialism is superordinate to 
two types of acronyms - alphabetic acronyms and orthoepic acronyms - in this research for detailed discussion, she, in agreement with Quirk et al. [1985: 1580-1584], Plag [2003: 160-164], and Mattiello [2013:65], labels the orthographic acronym "initialism." In short, this research adopts the term "abbreviation" as the general term for initialisms and acronyms. The focus of the discussion is on acronyms, though initialisms are also discussed as they are often involved in discussing acronyms.

Before discussing the shortening process, several terms referring to the abbreviation source, the semantic relation among the words in the source, and the orthographic style of the abbreviation are introduced here. In the study of abbreviations, the source structure of the shortened parts is called a "multi-word source," "source words/items" (Cannon[1989]; Kreidler [2000: 957]), "multi-word sequence" (Plag [2003]), or "source phrase" (Mattiello [2013:87]); and the result of the shortening process is called "reflex" (Kreidler [2000: 957]). This paper uses the term "source word" to refer to an individual word in the source phrase. Furthermore, in his research results, Cannon [1989: 109] found that the source structures of acronyms are all nouns: modifying prepositional phrases, existing abbreviations, compounded compounds, conjoined compounds, inflected forms, and affixed forms [1989: 119].

13 Furthermore, Kreidler [2000: 957] distinguishes blending, clipping, and abbreviation in terms of the semantic relations of their source phrases. Unlike blends where the semantic relation of the source can be syntagmatically (portable light $\ll$ portalight) or paradigmatically (breakfast lunch $<<$ brunch) related, the abbreviation sources are always paradigmatically related Benelux $\ll$ Belgium-Netherlands-Luxemburg. Similarly, the semantic relation of the source of the phrase of compound clipping is also syntagmatic (executive officer $<$ exec) Mattiello [2013: 116, 76]. Furthermore, unlike clipping and blending, where the retained parts give a clear clue of the source words, due to their minimal representation of the source words, acronyms need to be accompanied by their expansions (the sources). Jacobs et al. refer to this as "local acronyms," whereas the non-locals are not followed by the expansion [2020:2]; Mattiello [2012], for example, finds that among English and Italian scientific discourse, English abbreviations are well-accepted, and often expansions are not needed when the concepts are universally known. However, for local concepts, the local abbreviations need expansion in English. Expansions are also necessary for homonym acronyms with

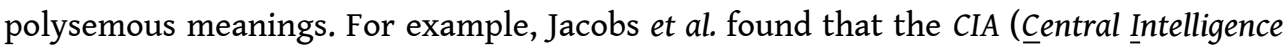
Agency) may be reinterpreted by other possible expansions depending on the context,

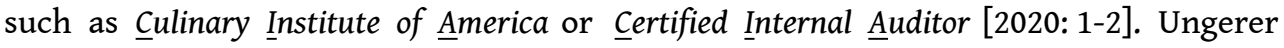
[1991: 132-133] also suggests that some additional motivations, such as phonological, morphological, and semantic motivations, are required to understand the meaning of brand names formed in acronyms.

14 The result of the shortening process is the orthographic structure of the abbreviation. Plag suggests that the orthographic characteristics, either initialisms or acronyms, can be presented in lower case or upper case: e.g., asap or CIA. Moehkardi [2016: 327] found that some acronyms are written in both lower and upper case; for example, MODEM or

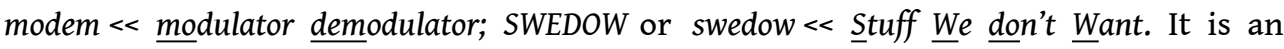
initialism when periods are used, as in a.s.a.p, where the letters are spelled individually. The use of capital letters in acronyms indicates a strong link to the base words from which the acronyms originate. The opposite is true to the use of lower case in which the original base words are no longer related, e.g., NATO in contrast to radar [2003: 162- 
163], at which point the acronyms are entirely accepted as words (Stockwell \& Minkova [2001:7]). Usually, to name official establishments, initialisms and acronyms are written in capital letters. Various writing styles are used for less formal abbreviations created for fun, for example, initialism such as $B 2 K \ll$ back to the keyboard, which includes numbers; kiss $<<$ keep it simple stupid, which consists of a clause; or a symbol XoXo $<$ hugs and kisses. Some abbreviations may also be pronounced as a combination of initialism and acronym, for example IUPAC /'aiju:pæk/ < International Union of Pure and Applied Chemistry or G-SIFI /'d3i:sæfaI/ « Global-systematically Important Financial Institution. Others are in compound formation with a dash to separate ACTS-UP, MALDITOF, or without a dash, MALDI-TOF MS.

The shortening process of initialisms and acronyms is similar to other types of shortening: clipping and blending. These types of shortening are similar because they are regarded as undergoing a non-morphemic process in their formation. According to Fandrych [2008], such a process uses at least one sub-morphemic element; it can be a splinter, a phonestheme, part of a syllable, an initial letter, a number, or a letter used as a symbol [2008:107]. The term "splinter," introduced by Berman [1961:279] and modified by Adams [1973] as neither a morpheme nor compound-element, was classified by Soudek [1978] into initial splinters and final splinters. López Rúa [2002: 38] further developed the concept as "those graphic and phonemic sequences which are neither inflectional nor derivational morphemes, nor combining forms (electro-, scope), and whose length generally allows their identification as belonging to a previous word." Furthermore, López Rúa explains that splinters tend to be syllables or units larger than syllables in their sources. When they are shorter than syllables, their constituents are the syllable onset (i.e., the prevocalic consonant or consonants), the onset and the nucleus (prevocalic consonants + vowel), or the rhyme (vowel + prevocalic consonants or coda) [2002: 38].

Blending often overlaps with acronyms and compound-clipping. Whereas in acronyms, the source can be more than three words, in blending, the size of the source words, which can be clipped and blended usually is up to three words, for example, Japornimation « Japan porn animation. Like clipping, the shortening in blending may occur in the initial, medial, or final part of the word. Another similar characteristic shared by clippings, acronyms, and blends is that one or two of their constituents in the source may not be shortened. Whereas, in clippings and acronyms, the unshortened words can also be unrepresented in the new formation, in blends almost always have all the source words represented - shortened, or unshortened. Here is an example of a compound-clipping, typo < typographical error. Only the initial retained part is the final product, and the second word is unrepresented in the final product. Unlike a clipping, an acronym is an arrangement of retained parts of the source phrase in which all or some of its constituents are shortened, for example, PETA $\ll$ People for the Ethical Treatment of Animals. Whereas most acronyms are combinations of one to three letters retained from each word of all or some words in the source phrase, blends may have more. From the source words, a blend may consist of two splinters; a splinter and a full word, splinters with overlap, a splinter and a full word with overlap, or overlap of full words (Fandrych [2008: 113]). Japornimation, for example, involves an overlap splinter Jap + overlap full word porn + overlap splinter - nimation (Mattiello [2013:122]). Overlapping does not usually take part neither in acronyms nor compound clippings. 
Therefore, the most significant difference between blends and acronyms is that blending allows overlapping.

Most English acronyms retain the initial letters of the source phrase (Cannon [1989]; Kreidler [1979, 2000]; Mattiello [2013]; Plag [2003]; Quirk et al. [1985]). However, Stockwell and Minkova [2001:7] agree that a larger part of the source word occurs in the English acronym that is "half-way between blends and acronyms." Here are examples of acronyms composed of three- to four-letter splinters retained from the source word(s), BITNET $\ll$ Because It's Time Network; TRADE $\ll$ Training Devices and Equipment (Alashqer [2016]); and Univac $\ll$ Universal Automatic Computer (Kreidler [2000: 958]).

Indonesian acronyms, on the one hand, employ initial, medial, and final letters, for example, IDI $\ll<$ Ikatan Dokter Indonesia (Indonesian Medical Doctor Association) uses all initial letters; while Kades $<<$ Kepala De-sa (the head of the village) consists of initial, medial letters, and initial syllable + medial letter. On the other hand, they may also retain initial, medial, and final syllable or more than a syllable, for example,

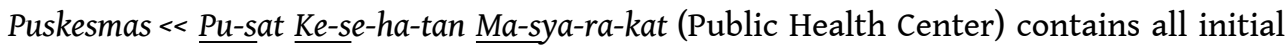
syllables and an additional one letter: litbang $\ll P e-n e-l i-t i-a n$ dan Pe-ngem-bang-an (Research and Development) consists of medial and final syllables. The dashes indicate syllable borders (Chaer [2008]; Kridalaksana [1989]; Notosusanto [1979]; Soeparno [1985]).

Similarly, Kreidler [2000: 958] also observes that for the sake of the acronym formation, "which is not only pronounceable but also euphonious or suggestive of some other meaning, the letters of the source form are sometimes chosen at will and vowel letters may be added" (the italic is my emphasis). Even Makkai [1974] and Kreidler [2000: 958] indicate that the makers of acronyms often start with a word "which allows the establishment of convenient semantic connections with the future acronym, then build the phrase." The semantic connotations can favor or prevent the orthoepic realization of the acronym. For example, CARE $\ll$ Cooperative for American Relief Everywhere. This strategy of constructing an acronym insinuates there are further possibilities for English acronym rules.

Another interesting feature in the study of abbreviation is its recursive nature. The steady demand among scientists to succinctly name their innovations and the growing popularity of abbreviations among wider language users allow them to be used in other formations. Two methods are applicable. The first method can be used when the new formation coincides with the word or an abbreviation in the source; see Mattiello [2013] and Word Spy (Recursive Acronym [1997]) and more current examples in Wikipedia (Recursive Acronym [2021]). The second can be used when the new abbreviation which includes other abbreviations in the source phrase but does not coincide. Nikafrooz et al. [2014] call acronyms which contain an internal acronym "double and triple acronyms". They use the term acronym the same way I use abbreviation. They divide acronyms into word acronyms - NASA - and spelling acronyms - NFL - similar to Kreidler [2000]: orthoepic or sounding acronyms - NATO - and alphabetic naming - UK. The former is called a "recursive acronym"; I propose to label the latter "multipleabbreviation" rather than double and triple acronyms, anticipating further formation involving previously coined abbreviation in the source phrase.

21 "Recursive acronyms" (see Mattiello [2013]) are commonly found in computing circles. Word Spy defines it as "an acronym that refers to itself, usually by incorporating the 
acronym as the first word in the expanded phrase" (Recursive Acronym [1997]). The examples found in Word Spy are ZWEI $<<\underline{Z} W E I$ Was EINE Initially; EINE $<<\underline{\text { EINE }}$ is not EMACS;

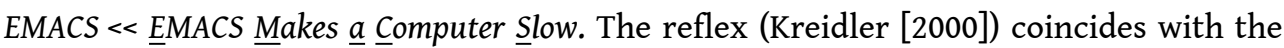
same acronym or word (in italic) in the source phrase. These humorous acronyms refer to themselves or other acronyms. These were common among hacker community members in the 1970s (Recursive Acronym [2021]). Recursive Acronym [2021] also provides more examples (also quoted by Mattiello [2013]), such as ALLEGRO $\ll$ Allegro Low-Level Game Routine, AGFA $\ll$ Always go for AGFA. This acronym EPROM $\ll$ Erasable Programmable $\underline{R O M}$ can be considered a recursive acronym. The ROM in the acronym coincides with an internal abbreviation in the source.

In "recursive acronyms", the recursive value lies in the repetition of the reflex and a word in the source phrase. In "multiple-abbreviations" the reflex is not a repetition of any word in the source. Still, it is a formation composed of the retained parts of the source to which an abbreviation belongs. The abbreviation in the source phrase is labeled internal abbreviation and is usually from the earlier level of formation. The following acronyms illustrate multiple-abbreviation: ACT-UP $<<$ AIDS Coalition to $\underline{\text { Unleash }}$

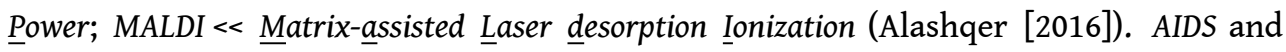
Laser are regarded as the internal acronyms of the new acronyms.

In Nikafrooz et al.'s study [2014: 251-252], they called a "double acronym" for an acronym whose source has an internal abbreviation... When the double acronym becomes an internal abbreviation in the source phrase of the higher level of formation, the result of the shortening process is called a "triple acronym." Unlike the recursive acronym, the newer reflex in multiple abbreviation does not coincide with the abbreviation in the source phrase. The following is the tree diagram produced by Nikafrooz et al. [2014:254], showing the recursive process of a double and triple acronym: TGSS, TONS, and TDRSS.

Figure 1. Tree diagram in Nikafrooz et al. [2014: 254]

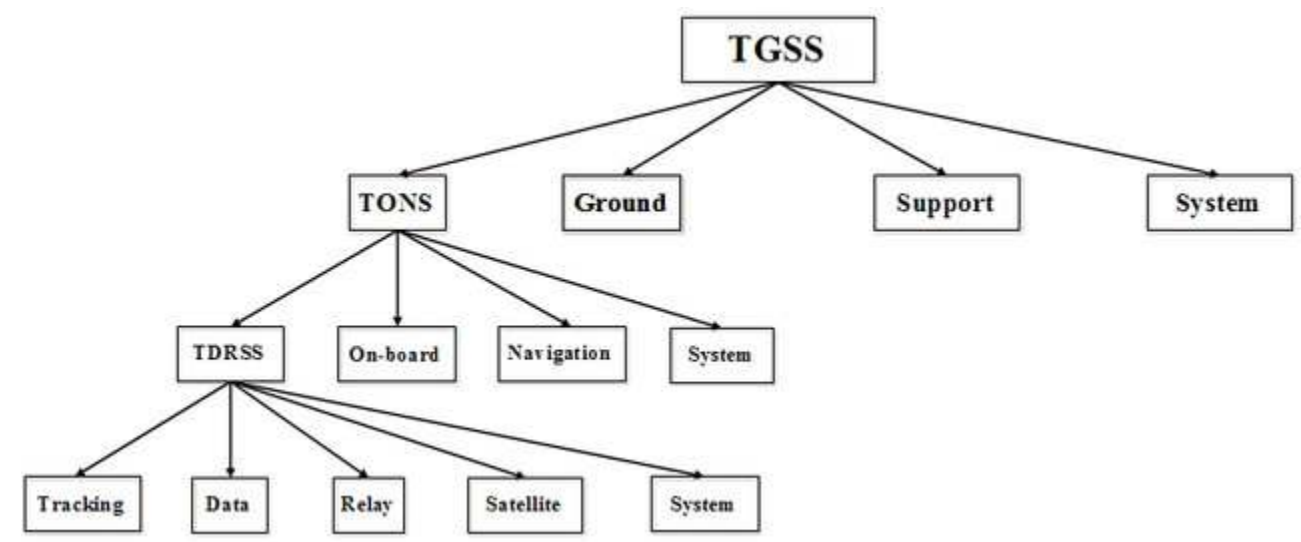

In this tree structure TONS is the double acronym as it has the internal abbreviation TDRSS in its source. In the next level of the formation, it becomes an internal abbreviation in the second level source phrase. The resulting acronym TGSS does not coincide with the constituents in the source but is represented by the initial $T$ of TONS. TGSS is labeled "triple acronym." A double or triple acronym may have more than one internal abbreviation in its source, for example, a double acronym NCHSTP $\ll$ National $\underline{C}$ enter for $\underline{H} I V, \underline{S} T D$, and $\underline{T} B$ Prevention. The tree diagram shows the recursive process of newer, higher-level abbreviations. Therefore, multi-abbreviation is appropriate to 
explain the whole recursive process, as it potentially continues. It is labeled "multiple" as it contains the external abbreviation (the reflex) and internal abbreviation in the source. As illustrated above, each innovation requires a new name. The new name could draw from the previous name that is already an abbreviation in the source phrase. This recursive nature follows Chomsky's generative and recursive model in which "acronyms can be generated based on some recursive rules in which each acronym carries one or more acronyms inside its internal structure." (Nikafrooz et al. [2014: 250]). I suggest the reflex determines the sub-type, either multiple-initialism or multiple-acronym, regardless of the internal abbreviation, initialism, or acronym.

However, the two processes of recursive and multi-abbreviation at some point may intersect. MALDI is an example of "multi-abbreviation" at its earliest level, as it has an acronym laser in its source phrase. However, in its development, the process can turn recursive. The acronym MALDI is repeated over in the source phrases to create a new name that coincides with the origin acronym in the source phrase. It began with MALDI $<<$ Matrix-assisted Laser desorption/Ionization, then the second level of formation MALDI-TOF $\ll$ MALDI Time-of-Flight, and then the third level of formation MALDI-TOF MS $\ll$ MALDI- TOF Mass Spectrometry (Calderaro et al. [2015]). MALDI and MALDI-TOF, the internal acronyms in the source phrases, coincide with the respective reflexes. The use of MALDI in the continuing levels of the abbreviation shows the process of "recursive acronym."

With this overflow of new abbreviations, their use is often restricted to the community where they originated. Still, sometimes a term gains popularity in wider language user circles. When a term is well-accepted, it may - like any other word - undergoes grammatical changes through affixation and conversions (de Vries [1970]; Fandrych [2008]). Just as the English acronym, ufo became ufology, many Indonesian abbreviations have also become lexicalized and undergone affixation. For example, the initialism PHK $\ll$ Pemutusan $\underline{H}$ ubungan Kerja (job dismissal) can be used as a base word that becomes a verb through memPHK (mem- indicating active voice) or diPHK (di-indicating passive voice) with or without a dash in between the prefixes me- and di-. Similarly, in English, the initialism PC (politically correct) may get a prefix un- to form unPC (not politically correct) or RSVP (Respondez S'il Vous Plait > please respond) is converted into the verb to RSVP (Fandrych [2008: 110]).

Well-known abbreviations may inspire the birth of new homonyms with polysemous meanings. For example, the acronym FBI (Federal Bureau of Investigation) may be reinterpreted by other possible expansions, such as Famous, Beautiful, Intelligent (on a Tshirt). Another example is TIA $<$ Transient Ischemic Attack (a medical term for "stroke"), Thanks in advance (a texting term) (Cahn [2021]), or $\underline{T}$ ruth in $\underline{\text { Advertising (internet }}$ journalism) (Peterson [2019]). The constant overflow of new initialisms and acronyms is often overwhelming, even with their respective expansions. The editors of the Journal of Epidemiology declared a BAN (Banish Acronyms Now) because of their frustration at receiving more and more new abbreviations within submissions, many of which are similar in form but with different meanings.

27 Even though English is regarded as a foreign language in Indonesia and English in Indonesia is in the "expanding circle" according to Kachru's concentric circles of English [1986], English has been used in formal and informal situations in Indonesia thanks to education and globalization. This language contact, as suggested by Thomason [2010], can occur through written language, through which most of the 
Indonesian population acquires their English. Furthermore, Thomason [2001: 7] also suggests that "casual contact is expected to lead to lexical borrowing" and therefore "less prone to non-material (i.e., structural borrowing)" (Renner [2018: 7]). Indeed, English borrowing in Indonesian mostly covers the area of the lexicon. Many of the English loanwords have been included in the Dictionary of Indonesian Language; many of which have been through the following four processes of adaptation of foreign language lexicon, including English: (a) the process of adaption of the spelling and pronunciation of "microphone" becomes mikrofon /mīkrofōn/; (b) not adapting the spelling but adapting the pronunciation of "bias": /baiəs/ becomes /biss/; (c) adapting the spelling but not adapting the pronunciation: "bomb" becomes bom with the same pronunciation /'bom/; "release" becomes rilis /rI'li:s/; (d) not adapting either spelling or pronunciation, for instance, "golf" and "hot dog," see Moeliono et al. [2005]. Weinreich [1979], in his study, also mentioned loan translation. In the process of loan translation, Indonesian translates English words or expressions to Indonesian. For instance, "conveyor belt" - sabuk berjalan; "skyscraper" - pencakar langit.

However, as shown in the examples of various word-formations using English words above, they illustrate that the English words used in public are not necessarily those recorded in the dictionary. Nevertheless, the norms adopted are not necessarily English. For example, Chicken wing KingWing follows the Indonesian structure: descriptor + proper name, whereas English is the opposite "Kentucky Fried Chicken." Another example is GeNose C19 $\ll$ Gadjah Mada Electronic Nose Covid-19. This elliptic acronym sacrifices one content word, and it retains the initials of each selected word of the source. It represents one content word in the acronym resulting in a combination of acronym and initialism. Although English recognizes extended acronyms, the retained part usually extends to one or two letters. In Indonesian extended acronyms, they may have more letters, even the whole word "Nose."

Unlike what has been stated by Kachru that people in the Expanding Circle are "norm dependent" [1986], Canagarajah [2006] believes that people in the Expanding Circle are developing new norms while speaking English to non-Inner circle English speakers. Although the general Indonesian population does not speak English in daily communication, English is used among certain circles and for specific purposes: education, work in multinational contexts, or businesses. For example, in the education field, the production of English acronyms is common among both the professors and the students. Whereas the professors produce, in general, rule-oriented acronyms, their students, representing the younger generation, may produce more creative, playful English acronyms for their school events. Their English better reflects the position of English in Indonesian.

\section{Theoretical framework}

As this research is about English acronyms in an Indonesian setting, I will adopt the framework designed by Mattiello [2013] to analyze the shortening processes, the grapheme order, and the semantic values of the acronyms. The Indonesian shortening rules (Soeparno [1985]) are used as a reference for the length of the shortening and the position of the retained parts of the source words.

31 Amidst the dynamic development of theories about this word-formation process, Mattiello [2013: 87-90] proposes a clear-cut classification of English acronyms. She 
classifies acronyms into morphotactic and morpho-semantic categories. Whereas the morphotactic classification deals with the representation and the shortening process of the acronyms, the morphosemantic classification deals with the form of the acronyms concerning their meanings. The morphotactic classifies a) which of the source words are represented in the acronyms (non-elliptic acronyms and elliptic acronyms); and b) how the shortening process and the retained parts adapt in the acronyms.

The focus of the analysis on non-elliptic and elliptic acronyms is whether the words in the source phrase - either the content or grammatical words - are shortened and then represented in the acronym. The second sub-classification of the morphotactic discusses the shortening process, which results in the initial, medial, or final retained parts of the selected words of the source and the process of ordering them into an acronym. The discussion in this section also includes a discussion of 1) additional inclusion of a vowel that does not belong to the source phrase in the acronym; 2) the retained parts that extend to more than a single letter; 3 ) the inversion of the retained parts of an acronym; 4) acronyms that coincides with one word of the source phrase.

The main reason for shortening an acronym is to reach pronounceability, euphony, or suggestive meaning. The pronounceability is the principal requirement for a shortening product to be labeled an acronym. The euphonic acronyms sound pleasing, even suggestive, as they remind people of something positive or negative. Although the original meaning of an acronym can only be motivated by its extension, homonym or homophone acronyms that match existing words may suggest positive or negative meanings depending on the acronym. Therefore, some adjustments to Mattiello's framework such as extra-letter addition and multiple abbreviations are proposed. Whereas the former extends the vowel addition, the latter refines the recursive acronym. Mattiello's framework, adopted with some adjustment, enables the researcher to map out all Indonenglish acronyms found in this research.

In Mattiello's framework, as also suggested by Cannon [1989] and Kreidler [2000], a vowel addition to the acronym is allowed, for example, in WREN $\ll$ Women's Royal Naval Service [2013: 88], the vowel $E$ does not belong to any words in the source and is added. In this current research, a consonant is added, but not a vowel, for the same reason of pronounceability, euphony, or suggestive meaning of the acronym. Acronym coiners usually utilize an additional vowel/consonant if they fail to find the needed letter to make the reflex pronounceable. Therefore, the following strategies are typically taken to enhance the pronounceability.

Extending the retained part beyond a single letter can be used for that purpose. In her definition of extended acronyms, Mattiello asserts that extended initials come from more than one initial letter from at least one or two word(s) of the source phrase. She gives an example of the extended acronym colidar (Coherent Light Detecting and Ranging) (Mattiello [2013: 89]). Thus, extended initials in the example provided are from two origin words of the source phrase. More importantly, an extended initial refers to an initial and one letter next to it. However, as also suggested by Stockwell \& Minkova [2001], Kreidler [2000] and Alashqer [2016], the retained parts are made longer. In this study's data, the length of the letters retained can be longer and the letters retained are not only from the initial but also medial and final position of the source words; therefore, the Indonesian shortening rules are consulted. Another strategy to reach the acronym pronounceability mentioned in Mattiello's framework is the inverted acronym. According to Mattiello [2013: 89], inverted acronyms are formations in which 
the ordering of some letters is changed. For example, in MISHAP $\ll$ Missiles High-Speed Assembly Program, the letters $H$ of "high" and $S$ of "speed" are inverted for the interest of pronounceability and homophony. Interestingly, in Indonesian acronym formation, inversion is not found.

The recursive acronym in Mattiello's framework is to classify acronyms whose form coincides with a word in the source phrase, for example, CAVE $\ll$ Cave Automatic Virtual Environment (Mattiello [2013: 89]). The acronym coincides with the source word "cave." This construct is also seen in Indonesian acronyms, such as Basarnas $\ll \underline{B a d a n} \underline{S A R}$ Nasional; SAR is the English acronym of Search and Rescue - the National body of SAR (JakartaPost [2010]). Because the internal acronym SAR coincides with the higher-level acronym, this process fits the Recursive Acronym in Mattiello's framework.

Despite its similar recursive manner, "multiple abbreviation" does not coincide with the constituents of the source phrase in which involves an internal abbreviation. Here is an example, ACT-UP $\ll$ AIDS Coalition to Unleash Power; the new acronym has a lower level of abbreviation process of the acronym AIDS. The lower-level acronym AIDS is represented by its initial in the higher-level acronym ACT-UP, which does not coincide with the constituents of the source phrase. ACT-UP is an example of a multiple acronym because the reflex is an acronym, regardless of the internal abbreviation. The reflex can also be a multiple initialism NRDN $\ll$ NOAA Radar Data Network in which the internal abbreviation are two acronyms NOAA and Radar. The expansion of each level of the abbreviation is required to decode the meaning of the later abbreviation. In other words, the expansion of NOAA and Radar is required to understand the later abbreviation, an initialism: NRDN (Nikafrooz et al. [2014]). Multiple abbreviations fit the potential recursive formations that originate from a lower level of the formation process. However, the higher level of abbreviation does not coincide with the source, and the internal abbreviation is only partially represented, usually by the initial letter of the abbreviation.

The morpho-semantic classification deals with semantic criteria, including acrostics. Conti \& Mattiello [2008:563] define acrostics as "acronyms whose reading/ pronunciation coincides with a homophone word in the English language." The identified homophony can contain either semantically irrelevant or semantically relevant acrostics. The former focuses on similar forms to existing words in English with no semantic connection, for example, SWOT $\ll$ Strength, Weakness, Opportunity, and Threat; the acronym SWOT has no semantic connection to the verb swot (Mattiello [2013:90]). The semantically relevant acrostic is a homophonous acronym to an existing English word. The meaning of the acrostic is connected to the meaning of the acronyms, for example, BASIC $\ll$ Beginners' All-purpose Symbolic Instruction Code; the acronym BASIC is related to the word beginners (Mattiello [2013: 90]).

Besides English rules, Indonesian rules for the acronym shortening process are also consulted to explain the length of retained parts and explain which parts of the original words are drawn from. This part of the process lies in the important difference between the two languages. The following is a brief description of the Indonesian acronym shortening processes. Despite various formulas proposed by Indonesian linguists, Soeparno's [1985] formula that shows how the morpheme in the word 
sequence is retained and represents how Indonesian acronyms operate. The following is the formula with the source phrases are given dashes indicating syllable borders:

- Pattern 1: first letter (consonant or vowel) of all content words (or also function words) usually in capital letters: IKIP $<<$ Institut Keguruan dan Ilmu Pendidikan (teaching institute);

- Pattern 2: first letter and the following letter; but it is not a syllable: ampera $<<\underline{a-m a-n a t ~ p e n-}$ de-ri-ta-an rak-yat (the mandate of the people's suffering);

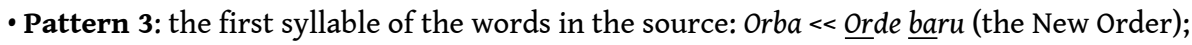

- Pattern 4: The first syllable plus one or more following phoneme(s): muntaber $<<\underline{\text { mun-tah }} \underline{\text { be- }}$ rak (vomiting and diarrhea);

- Pattern 5: the mid phonemes of a word, can be a syllable or a syllable with another phoneme: tilang $<<$ bukti pelanggaran (traffic ticket);

- Pattern 6: the final syllable of a word: mendagri $<$ men-te-ri da-lam ne-gri (minister of internal affairs);

- Pattern 7: a combination of the initial and mid part of a constituent: dolog > depot logistik (logistic hub); opstib < operasi tertib (obedience check);

- Pattern 8: a combination of initial and final letters: danki $\ll<$ komandan kompi (company commandant); irup $<<$ inspektur upacara (ceremony inspector).

An inverted pattern is not found in Indonesian acronyms (Chaer [2008]; Kridalaksana [1989]; Soeparno [1985]).

Whereas patterns 1 and 2 are similar to English rules where the acronyms are made from the initials and or initial and one or two following letters of each constituent of the source phrase, patterns 3 to 6 indicate the use of syllables or syllables plus another letter(s) of the initial, medial, and final part of the constituents. The retained parts in patterns 4,5 , and 6 are similar to a splinter, yet none overlap. Patterns 7 and 8 are combinations of the initial and medial or initial and final parts of the constituents.

\section{Data and methodology}

41 The data were collected from April to August 2018 from Instagram, and offline media, such as posters and billboards in Yogyakarta. They were part of a wider data set representing various brand names of local products, including events, created through various word-formation processes. Data without their extensions were rejected, so were names of non-school activities. School in this research included universities. Fifty data were selected. They were names of school events such as competitions, conferences/seminars, and festivals/carnivals. Although the data selected had to have English source phrases/extensions, they were not evaluated. All 50 sources were photographed either in their original environment or on Instagram. Before they were classified and analyzed further, the acronyms' length and source phrases were measured. Then, the data were classified and analyzed following Mattiello's framework [2013]. Soeparno's [1985] framework was consulted in the discussion of the shortening process and the order of retained parts in the acronyms. As an acronym does not only appear in just one table, it may have different reference numbers depending on what table and number it belongs to. For example, NASA (2.28) is located in Table 2, number 28, or NASA (6.3) is located in Table 6, number 3. Tables of distribution are presented in each section to give better quantitative information of each subclassification. 
The results of the analysis are divided into four sections: the first section discusses the representativeness of the words within the source phrase in the acronyms (non-elliptic and elliptic acronym), the second outlines how the letters were retained and positioned within the acronym (additional, extended, and inverted letters in the acronym), the third section discusses recursive nature of the multiple acronyms, and the last section discusses the semantic values of the acronyms.

\section{Results and discussion}

The length of the source words ranges from 3 to 9 words. Orthographically, the acronyms are English: for example, BEE and INJECTION are homonyms to existing English words. Some of them are English-like: for example, UNAC and ECA are nonexistent in the English lexicon, but their phonological patterns, VCVC and VCV, are acceptable in English. Some others are Indonesian acronyms, such as BAWA, a verb in Indonesian, or INOVASI, an Indonesian assimilation of the English word innovation. More importantly, all of the acronyms have English source phrases, except the names of the institutions. However, the accuracy of the structure of the source phrases was not evaluated. Graphemically, the acronyms have 3-11 letters, longer than those found by Cannon [1989] (3-9 letters). Structurally, the source items of the acronyms are noun phrases (e.g. BAWA $\ll$ Bali Animal Welfare Association), embedded-prepositional noun phrases (COMBAS $\ll$ Competition of Business Administration Skills), compounded compounds (IKOF $\ll$ Indonesia - Korea Festival), or conjoined noun phrases (IPPEC «< Indonesian Public Poster and Essay Competition). The following two tables represent the whole data collected and divided into non-elliptic and elliptic acronyms, preceded by a table of the distribution of the acronyms.

\subsection{Non-elliptic and elliptic acronyms}

According to Mattiello, in non-elliptic acronyms, none of the initial letters of the source words is unrepresented, including the function words [2013: 87]. On the other hand, in the elliptic, the function words are often left unrepresented in the acronym. Table 1 below is the distribution of non-elliptic and elliptic acronyms. There are more nonelliptic than elliptic acronyms in the data, meaning there are more acronyms whose constituents in the source phrases are unrepresented.

Table 1. Distribution of Non-elliptic and elliptic acronyms

\begin{tabular}{|l|l|l|l|}
\hline No. & Types of Acronyms Process Formation & Frequency & Percentage \\
\hline $\mathbf{1}$ & Non-elliptic acronyms & 29 & 58 \\
\hline $\mathbf{2}$ & Elliptic acronyms & 21 & 42 \\
\hline Total & 50 & 100 \\
\hline
\end{tabular}

Table 2 contains non-elliptic acronyms and discusses how all the words in the source phrase are retained, yet the retained parts are not always the initials of the source 
words. Table 3 presents the elliptic acronyms and discusses what source words are not represented in the acronyms.

Table 2. Non-elliptic acronyms

\begin{tabular}{|c|c|c|}
\hline No. & Acronym & Meaning \\
\hline 1 & ASEC & Airlangga Smart Entrepreneur Competition \\
\hline 2 & BAWA & Bali Animal Welfare Association \\
\hline 3 & ELUC & English Letters Undergraduate Conference \\
\hline 4 & IFOPH & Islamic Fair of Public Health \\
\hline 5 & IREC & International Relations English Competition \\
\hline 6 & NEO & National English Olympiad \\
\hline 7 & SDSAC & Sanata Dharma Smart Accounting Competition \\
\hline 8 & UNAC & UNAIR National Accounting Competition \\
\hline 9 & CosMIC & Carnival of Sensation Music Cooperative \\
\hline 10 & BEE & Biology Education Expo \\
\hline 11 & UTIC & UAD Teaching International Conference \\
\hline 12 & ЕВОТЕС & ELINS Robotic Competition \\
\hline 13 & CEPTION & Chemical Engineering Paper Competition \\
\hline 14 & EPTION & Enviro Paper Competition \\
\hline 15 & ECSOS & Economic Solutions \\
\hline 16 & MANIAC & Multimedia and Interactive Art Competition \\
\hline 17 & IKOF & Indonesia-Korea Festival \\
\hline 18 & UWEST & UNDIKSHA Writing Contest \\
\hline 19 & SEVENTSEAS & Sharia Economics Event South East Asia \\
\hline 20 & NEXT & National English Exhibition \\
\hline 21 & INETOR & Indonesian Next Top Manager \\
\hline 22 & CERCo & Chemical Engineering Research Competition \\
\hline 23 & NESCO & National Electronic Power System \\
\hline
\end{tabular}




\begin{tabular}{|l|l|l|}
\hline 24 & ARISE & Administration Impacts Society \\
\hline 25 & DEFINE & Diponegoro Financial National Competition \\
\hline 26 & SPACE & Sharia Paper Competition \\
\hline 27 & INJECTION & Science Project Competition \\
\hline 28 & NASA & National Scientific Days \\
\hline 29 & CHESPECTION & Chemical Engineering Scientific Paper Competition \\
\hline
\end{tabular}

Table 2 shows 11 data meeting the requirement of the non-elliptic acronyms model: only the initials are retained from the source sequence. There are three source phrases using function words: the preposition of and the conjunction and. There are another 20 acronyms that can be included in the non-elliptic category, considering the representation of every constituent of the source phrase. Among the 20 acronyms, the represented parts include medial letters and final letters; for example, in datum 2.25, the two medial letters of $E$ in Diponegoro and Competition are represented in the acronym; in datum 2.21, the final letter $R$ in Manager is represented in the acronym. The table also shows that the representation in the acronyms is not only letters but also splinters like est out of the word contest in datum 2.18, and the splinter ent out of event in datum 2.19, and also syllables. For example, data 2.13 and 2.14, show that final syllables tion are retained from competition and represented in the acronyms. In datum 2.29 , although the initial letter is retained, the final syllable is also retained. The inclusion of the non-initial letter, a splinter, a combination of initial letter and final syllable, or final syllable in the acronym results in an improved acronym pronounceability. There are 10 homonyms: 2.6, 2.9, 2.10, 2.16, 2.20, 2.24, 2.25, 2.26, 2.27, 2.28 and 1 homophone: 2.19 .

The table also shows some source phrases $(2.8,2.11,2.12$, and 2.18) containing abbreviations of various educational institutions: UNAIR, UAD, ELINS, UNDIKSHA. There are three other institutions included in the data that are not abbreviated, but the word universitas (university) is excluded from the description: (2.1) Airlangga, (2.7) Sanata Dharma, and (2.25) Diponegoro. Including the names of the institutions confirms that the events were held by higher educational institutions representing the educated population of Indonesians in which English is required and practiced. Datum 1.14 includes a clipped word in the source phrase: enviro instead of environment, indicating a free choice of clipping, yet maintaining the meaning of the word.

Table 3. Elliptic acronyms

\begin{tabular}{|l|l|l|}
\hline No. & Acronym & Meaning \\
\hline 1 & BICOLE & Bandung International Conference on Language (and) Education \\
\hline 2 & EPIC & Economic Paper (of) Indonesian Condition \\
\hline
\end{tabular}




\begin{tabular}{|c|c|c|}
\hline 3 & GAMA ICIAF & $\begin{array}{l}\text { Gadjah Mada International Conference (on) Islamic Accounting (and) } \\
\text { Finance }\end{array}$ \\
\hline 4 & GAMA ICIED & $\begin{array}{l}\text { Gadjah Mada International Conference (on) Islamic Economics (and) } \\
\text { Development }\end{array}$ \\
\hline 5 & BEASt & Business Entrepreneurship (and) Advertising Strategy \\
\hline 6 & ICMA & International Conference (on) Multidisciplinary Academic \\
\hline 7 & IPPEC & Indonesian Public Poster (and) Essay Competition \\
\hline 8 & ECA & English Contest (of) Animal (Science) \\
\hline 9 & AMFETAMIN & Airlangga Farmasi (on) Essay Islamic Competition \\
\hline 10 & INOVASI & Indonesian Youth Festival (of) Science \\
\hline 11 & PROSITION & Protocol (of) (IKIP) Siliwangi Competition \\
\hline 12 & CHEEPS & Chemical Engineering Planner (for) (Better Future) \\
\hline 13 & ALCOFE & Annual Conference (of) Economics Forum \\
\hline 14 & ECTION & Economic (Writing) Competition \\
\hline 15 & COMBAS & Competition (of) Business Administration Skills \\
\hline 16 & ICOM & IT (and) Computer \\
\hline 17 & GRAVITATION & (The) Greatest Victory Celebration (of) Communication \\
\hline 18 & REACTION & Research (of) Applied Chemistry Competition \\
\hline 19 & TENSES & Teenager English Competition (in) SMANsasi \\
\hline 20 & SOUNDSPEAK & Seminar (of) Announcing (Skill) and (Public) Speaking \\
\hline 21 & EXTALTION & Explosion (of) Digital Creation \\
\hline
\end{tabular}

In contrast to the data in Table 2, all source phrases in this table contain prepositions, conjunctions, and articles that in the elliptic acronym are unrepresented. Table 3 shows that the coiners leave some words in the source phrase unrepresented (in brackets). Most grammatical words, such as prepositions (of, on, etc.), conjunctions (and), and article (the), are unrepresented. However, the preposition on in datum 3.1 and the conjunction and in datum 3.20 are represented in their respective acronyms. Although Canon [1989] concluded that most function words could be ignored, he also found in his study that content words were also occasionally unrepresented. In this research, too, there are content words unrepresented: nouns: science (3.8), writing (3.14), skill (3.20), and adjectives: public (3.20); also note a noun phrase IKIP (3.11), an acronym of an education institution, and a prepositional phrase (3.12) for better future. Datum 3.9, 
intentionally or unintentionally, includes one Indonesian word for pharmacy, and the acronym contains the Indonesian spelling of amphetamine. Table 3 also shows that some source phrases contain the names of educational institutions: (3.11) IKIP Siliwangi, a teaching institute, and some reduced names: (3.3 and 3.4) Gadjah Mada and (3.9) Airlangga leaving out their descriptor universitas (university).

Acronyms 3.1-3.8 are composed of the initials from the content words of the source phrases. In datum 3.5 the acronym consists of all initial letters of the selected words; however, to reach a euphonic and more suggestive pronunciation, the initial letter of the final selected word is extended to the next letter st, resulting in the acronym BEASt. In the acronyms 3.9-3.21, the represented letters are not only initials but also medial and final letters of the individual words in the source. The acronyms can be a combination of initial, medial, and final letters of the source words. For example, SOUNDSPEAK (3.20) consists of initial $s$, medial oun, final $d$, and the initial syllable speak from the represented words. The inclusion of the syllable speak in the acronym also enables the prospective participants to understand what the event is about. Structurally, the inclusion of a full word in an acronym is rare in English.

From the discussion above, it is evident that the elliptic acronym makers could exclude content words, for example, skill and public in datum 3.20 SOUNDSPEAK, or include a function word, for example, the preposition of in datum 2.9 COSMIC or the conjunction and in datum 3.1 BICOLE. They could also select the retained parts of the source words in initial, medial, or final parts of the source words in the source, as illustrated in the previous paragraph, to create pronounceable acronyms.

\subsection{Shortening processes and grapheme order}

51 Retaining the initials of the words in the source phrase is the primary rule in acronym formation. However, for the sake of the acronym's pronounceability or euphony, a few exceptions of reordering the retained parts in the acronym-to-be or letter extension and or additional vowels, which do not belong to any word in the source phrase, are also possible (Mattiello [2013: 88]).

Table 4. Consonant addition

\begin{tabular}{|l|l|l|}
\hline No. & Data & Meaning \\
\hline 1 & CHEEPS & Chemical Engineering Planner (for Better Future) \\
\hline
\end{tabular}

As shown in Table 4, a vowel addition is not found in this research, but a consonant addition is. The acronym CHEEPS (4.1) adds the letter $S$ at the end of the acronym; yet, the letter does not belong to any constituents within the source phrases. It is not clear why the makers added $S$ to the acronym. The best explanation I can offer is a phonological motivation. Should the acronym be CHEEP, the sound of the acronym would remind the coiner and listeners of cheap. The sound of CHEEPS could have reminded them of chips, which has a more positive connotation. Most coiners utilize other strategies to create their acronyms. The practical strategy the coiners adopt is consider which words to shorten, which part of the words should be shortened, and 
how much of the word should be shortened. The following table shows how the shortening process takes place beyond the retained initial letters.

In this research, the word retained for the acronym can include non-initials followed by succeeding letters or letters that are a few letters away from the first retained letter, as presented in Table 6 . Table 5 shows that the number of extended acronyms are almost equivalent to the number of single-retained letter acronyms.

Table 5. Extended Acronym

\begin{tabular}{|l|l|l|l|}
\hline No. & Types of Acronyms Process Formation & Frequency & Percentage \\
\hline $\mathbf{1}$ & Extended acronyms & 24 & 48 \\
\hline $\mathbf{2}$ & Single-retained letter & 26 & 52 \\
\hline \multicolumn{2}{|l}{ Total } & 50 & 100 \\
\hline
\end{tabular}

The single-retained letter acronyms can be observed in 2.1-2.11, 3.1-3.2, and 3.6-3. 8. Some of them result in homonyms: 2.6 NEO, 2.9 COSMIC, 2.10 BEE, some others are nonexistent words. Below is the discussion of the extended acronyms.

Table 6. Extended acronyms

\begin{tabular}{|c|c|c|}
\hline No. & Acronym & Meaning \\
\hline 1 & BEASt & Business Entrepreneurship (and) Advertising Strategy \\
\hline 2 & CERCo & Chemical Engineering Research Competition \\
\hline 3 & NASA & National Scientific Days \\
\hline 4 & IKOF & Indonesia-Korea Festival \\
\hline 5 & MANIAC & Multimedia and Interactive Art Competition \\
\hline 6 & CosMIC & Carnival of Sensation Music Cooperative \\
\hline 7 & GAMA ICIED & $\begin{array}{l}\text { Gadjah Mada International Conference (on) Islamic Economics (and) } \\
\text { Development }\end{array}$ \\
\hline 8 & GAMA ICIAF & Gadjah Mada International Conference (on) Islamic Accounting (and) Finance \\
\hline 9 & NEXT & National English Exhibition \\
\hline 10 & ARISE & Administration Impacts Society \\
\hline 11 & DEFINE & Diponegoro Financial National Competition \\
\hline 12 & SPACE & Sharia Paper Competition \\
\hline
\end{tabular}




\begin{tabular}{|l|l|l|}
\hline 13 & ECSOS & Economic Solutions \\
\hline 14 & INETOR & Indonesian Next Top Manager \\
\hline 15 & ICOM & IT (and) Computer \\
\hline 16 & COMBAS & Competition (of) Business Administration Skills \\
\hline 17 & SEVENTSEAS & Sharia Economics Event South East Asia \\
\hline 18 & EXTALTION & Explosion of Digital Creation \\
\hline 19 & CEPTION & Chemical Engineering Paper Competition \\
\hline 20 & EPTION & Enviro Paper Competition \\
\hline 21 & INJECTION & Science Project Competition \\
\hline 22 & CHESPECTION & Chemical Engineering Scientific Paper Competition \\
\hline 23 & SOUNDSPEAK & Seminar of Announcing Skill and Public Speaking \\
\hline 24 & EBOTEC & Elins Robotic Competition \\
\hline
\end{tabular}

Seven acronyms consist of one extended initial (6.1-6.7), and the rest contain more than one extended initial or extended non-initial. The initials of the final words in data 6.1 strategy and 6.2 competition are retained with the respective letter next to them.

Two data show their final words in the source retain their initials. One of them is followed by a consonant letter resulting in a homonym BEASt (6.1) that also suggests aggressiveness. The other is followed by vowel $O$ for pronounceability CERCO (6.2). The acronym COSMIC (6.6) shows an example of an initial followed by a non-immediate letter. The component $M I$ in the acronym is actually from initial $M$ and $I$, which are two letters away from each other: music. Extended components can also be taken from function words, like in the acronym MANIAC (6.5), the letters AN are from the function word and.

Under this classification, although the first retained letters are initials, the phonemes that follow are not the immediate letters but separated by 2-7 letters in between. This is similar to Soeparno's patterns 7 and 8, which reveal the combinations of initial and middle letters and initial and final letters, respectively. For example: to compose the acronym ARISE (6.10), the initial A from administration is combined with $R$ from the same source word that is separated by seven other phonemes; and the initial $S$, in society, is extended by $E$ separated by three letters. Another example is in the acronym ECSOS (6.13), the final letters SOS are taken from the same source word: Solutions, whereas $O$ is the immediately extended letter to the initial letter $S$, the last phoneme $S$ is employed through delayed extension, as six other phonemes separate it. This particular process follows Soeparno's pattern 8.

Furthermore, following patterns 5 and 6 , the retained parts can be extended by derivational suffixes, such as -tion. For example, in the acronym EXTALTION (6.18), the components tal and -tion are extended final letters (that are also syllables) of two 
content words (digital and creation). This acronym is certainly a non-existent English word, but phonologically, it is acceptable. The coinage of this acronym indicates the coiner's creativity and also knowledge of the English suffix. Datum INJECTION (6.21) shows that the first two letters of the acronym are not initials but delayed extended combinations of $I$ and $N$ separated by $E$ from the source word science.

Moreover, the medial component of the acronym JEC $(T)$ is the final splinter of the source word project. Similarly, the final part of the acronym is also the final part (T)ION drawn from the final source word competition. However, it is not clear how both final splinters are shortened. They are possibly overlapping, which is not common in English acronym rules as it surpasses the defined boundary of an acronym and becomes blending. Another possibility is that one $T$ is simply excluded. In datum 6.24 EBOTEC, for example, the retained components are in the middle: bot of robotic, a syllable, and letter $E$ out of competition possibly replacing the final syllable of robotic. The last letter in the acronym $C$ is either the final letter of robotic or the initial of competition; if so, it is inverted, preceded by the medial $E$ of competition. From this discussion, again it is confirmed that the shortening processes of these English acronyms follow Indonesian acronym rules where non-initial letters or components are used when constructing acronyms to arrive at morphologically acceptable English words.

This research also found that two shortening processes took place from a single source phrase, resulting in two different types of acronyms. This phenomenon of compound abbreviation is also common in Indonesian abbreviation, exemplified in the following acronym-initialism compound: Bakom PKB $<$ Badan Komunikasi Penghayatan Kesatuan Bangsa, a Communication forum of a Chinese ethnic organization (JakartaPost [2010]). The initial process applies extended initials $b a$ and $k o m$ whereas the rest of the source retained its single initial letters. This study found GAMA ICIED (6.7), GAMA ICIAF (6.8), and Table 2 SDSAC (2.7). In the acronym GAMA ICIED (6.7), the first process applies the extended initials of Gadjah Mada, a reduced name of Universitas Gadjah Mada. In contrast, the second process retains the initials of the content words and excludes the preposition on and the conjunction and in the source phrase, resulting in an elliptic acronym GAMA ICIED. The acronym GAMA ICIAF (6.8) also undergoes a similar process, and both result in compound acronyms as there are two sets of acronyms separated by a space. SDSAC (2.7), a non-elliptic acronym, has two initial letters $S D$ retained from Sanata Dharma, another reduced name of a university, and an acronym $S A C$, also the initials from the source words. SDSAC is an example of a combination of initialism and acronym with a combination of alphabetic pronunciation with orthoepic rules, like JPEG /'dzeIpeg/. So, the initialism is pronounced /esdi:/ and the rest of the letters is pronounced as an acronym /sək/. On the other hand, GAMA ICIED and GAMA ICIAF are compound acronyms, pronounced through a suggestive pronunciation /'gæmə aIsid / and /'gæmə aIsiəf/.

For the sake not only of pronounceability but also of euphony and/or suggestive meaning, some Indonesian acronym makers seem to take the liberty of forming acronyms from the source phrase by not only exploiting the immediate string of letters but also changing the order of the available letters to form the intended acronym. According to Mattiello, this formation process is the rarest and the most uncertain [2013: 89]. Nevertheless, in this research, five acronyms follow this strategy; moreover, the changes in the inverted position of the retained letters are more unpredictable. The 
following Table 8 shows how some data employ an inversion of the letter to obtain pronounceable and or suggestive acronyms.

Table 7. Inverted acronyms

\begin{tabular}{|l|l|l|l|}
\hline No. & Types of Acronyms Process Formation & Frequency & Percentage \\
\hline $\mathbf{1}$ & Inverted letter acronyms & 5 & 10 \\
\hline $\mathbf{2}$ & Non-inverted letter acronyms & 45 & 90 \\
\hline Total & 50 & 100 \\
\hline
\end{tabular}

Table 7 shows that there are not many inverted acronyms found in the data, possibly because of the more complicated shortening process and then positioning the retained parts. After undergoing such a complicated process, it is surprising that only 2 data results in homonyms: 8.3 GRAVITATION and 8.5 AMFETAMIN, the Indonesian version of amphetamine. The other 3 data are merely achieving acronym pronounceability.

Table 8. Inverted letter acronyms

\begin{tabular}{|c|c|c|c|}
\hline No. & Acronyms & Meaning & Inverted order \\
\hline 1 & ALCOFE & Annual Conference of Economics Forum & $\begin{array}{l}\text { Possibly } F E \text { in conference or } \\
\text { inversion } \mathrm{E}<<\mathrm{F}\end{array}$ \\
\hline 2 & NESCO & National Electronic Power System & $\mathrm{S} \ll \mathrm{C}$ \\
\hline 3 & GRAVITATION & $\begin{array}{l}\text { The Greatest Victory Celebration of } \\
\text { Communication }\end{array}$ & /at/ >> /ta/ in celebration \\
\hline 4 & ЕВОТЕС & E(1)lins Robot(2)ic Compe(3)tition & $\mathrm{I} \ll$ e $(\mathrm{I}$ is removed $)$ \\
\hline 5 & AMFETAMIN & $\begin{array}{l}\text { A(1)irlangga } \quad \mathbf{F ( 3 ) a r m ( 2 ) a s i ~ o n ~} \quad \mathbf{E}(4) \text { ssay } \\
\text { Islami(6)c Compet(5)ition(7) }\end{array}$ & $\mathrm{F} \ll \mathrm{m} ; \mathrm{ami}>\mathrm{t}$ \\
\hline
\end{tabular}

There are two possible ways of processing ALCOFE (8.1) $\ll$ Annual Conference of Economics Forum. Firstly, it could be interpreted as employing the first two of the five source words. However, if the coiner were more creative and did not want to waste the source, he could have adopted a simple inversion strategy. In that case, he could have adopted a simple inversion strategy by inverting the order of letters $E$ and $F$ from economics and forum, respectively. In the order of their word origin, $E$ should have come before $F$, but it comes after $F$ in the acronym. The inversion in NESCO (8.2) occurs when the initial $S$ of the final word system moves before $C$, the final letter of the second word electronic. Other non-initials are used within the acronym, $C$ the final letter of the second word and $O$ the second letter of the third word. In GRAVITATION (8.3), the inversion occurs in the syllable $T A$ in the acronym, originally from the splinter at in celebration. This is further evidence that non-initials and splinters are also considered in the formation of acronyms. Unlike the inversion in GRAVITATION, which occurs in the word celebration, 
the inversion in TEC of EBOTEC (8.4) comes from different words. The E in TEC comes from the non-initial $E$ of competition. It moves next to the medial letter $T$ of the previous word robotic and replaces the letter I in the final syllable of robotic. In other words, the inversion involves two words: robotic and competition. The last acronym with inversion is AMFETAMIN (8.5), an Indonesian spelling for amphetamine. This acronym has two inversions: a) the inverted order of letters $M$ and $F$, the medial and the initial letters, respectively of one single origin word farmasi, an Indonesian word for pharmacy; and b) an inverted order of medial letter $T$ of the final word competition and a medial splinter AMI from the preceding word Islamic. This is another example of two inverted words.

The shortening process and the grapheme order in this section can be summarized as follows. The word competition is taken as an example to summarize the retained patterns of a word. This word is among the most frequent words found in the data and was used 19 times. It can represent how a word can be retained in various ways: initial (6), extended (2), middle $E$ (4) or $T$ (1), final syllable tion (5), and combination initial letter and final syllable (1) $C_{-} \ldots$ tion.

The discussion of the shortening process and the grapheme adaptation in the acronyms shows that the acronym makers put a lot of effort into making the acronyms pronounceable and acceptable English words that the creators employ inversion, and also include a syllable - TION from the original word(s) in the source phrase into the acronym. The creators seem to understand that the names for their events should be a noun and that English nouns can be formed by adding the suffix -tion. The inclusion suffix -tion in the acronym formation is an easier way to form an acronymic name. Therefore, there are nine formations of acronym found in the data using-TION, four of which are English words: INJECTION, REACTION, GRAVITATION. The rest are incorrect or non-existent in English, despite the -tion suffix, for example, CHESPECTION, ECTION, CEPTION, EPTION, and PROSITION. They are also attempting to create compound words through their acronyms, such as SOUNDSPEAK and SEVENTSEAS.

\subsection{Multiple acronyms}

Multiple acronyms are a sub-type of multiple abbreviations. In these cases the acronym does not coincide with a constituent in the source phrase. In multiple acronyms, the acronym obtains its retained parts from the constituents, including an abbreviation, in the source phrase. It is a so-called multiple acronyms because the reflex is an acronym, and it has an internal abbreviation in the source phrase. Multiple initialisms occur when the reflex is an initialism, for example, $A M D<<A B R I$ Masuk Desa (the social service requirements of the Indonesian Army); $A B R I$ is an acronym in the internal abbreviation. The expansion of each level of the abbreviation is required to decode the meaning of the later abbreviation. In other words, the expansion of $A B R I$ is required to understand the latter abbreviation, AMD. Nikafrooz et al. [2014] highlights good examples of multiple initialisms. This research only found multiple acronyms of which source phrases contain an abbreviation: either initialism or acronym.

Table 9. Multiple acronyms

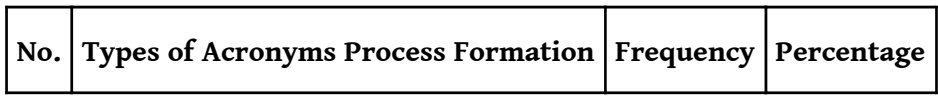




\begin{tabular}{|l|l|l|l|}
\hline 1 & Multiple acronyms & 7 & 14 \\
\hline 2 & Non-multiple Acronyms & 43 & 86 \\
\hline Total & 50 & 100 \\
\hline
\end{tabular}

Although the incidence is low, multiple acronyms are a possible strategy. This particular process is a common practice in scientific and computing circles. This could be the reason why some acronym makers in this study tried using this strategy in their acronym formation; besides, examples of this type of acronyms are also accessible on the internet and could influence acronym building processes. Below is the discussion of multiple acronyms found in the data.

\section{Table 10. Multiple Acronyms}

\begin{tabular}{|l|l|l|l|}
\hline No. & Acronym & Meaning & Internal abbreviation \\
\hline 1 & UTIC & UAD Teaching International Conference & UAD - Universitas Ahmad Dahlan \\
\hline 2 & UNAC & $\begin{array}{l}\text { UNAIR National Accounting } \\
\text { Competition }\end{array}$ & UNAIR - Universitas Airlangga \\
\hline 3 & EBOTEC & ELINS Robotic Competition & $\begin{array}{l}\text { ELINS - Electronic instrumentation - a } \\
\text { study program }\end{array}$ \\
\hline 4 & UWEST & UNDIKSHA Writing Contest & $\begin{array}{l}\text { UNDIKSHA - Universitas Pendidikan } \\
\text { Ganesha - Teaching University } \\
\text { Ganesha }\end{array}$ \\
\hline 5 & TENSES & $\begin{array}{l}\text { Teenager English Competition } \\
\text { SMANsasi } \quad \text { (in) }\end{array}$ & $\begin{array}{l}\text { SMANsasi - Sekolah Menengah Atas } \\
\text { Negri - public high school }\end{array}$ \\
\hline 7 & ICOM & IT (and) Computer & $\begin{array}{l}\text { IKIP - Institute Keguruan Ilmu } \\
\text { Pendidikan - teaching institute }\end{array}$ \\
\hline
\end{tabular}

The current research found three acronyms whose origin source phrases include initialisms (10.1 UAD, 10.5 SMAN, and 10.7 IT) and four, including acronyms (10.3 ELINS, 10.4 UNDIKSHA, 10.2 UNAIR, 10.6 IKIP). Except IT, the other internal abbreviations are in Indonesian. Moreover, both the internal initialism and acronym constituents (UAD, ELINS, UNDIKSHA, UNAIR, SMAN, IT) are treated like constituent words: they are reduced into initials. However, IKIP is unrepresented. Only UTIC (10.1) and UNAC (10.2) are nonelliptic; the rest are elliptic and include non-initials within the multiple acronyms. Except $I T$, the other abbreviations are names of institutions. 


\subsection{Semantic values of the acronyms}

This research found 19 acronyms that are homophonous to existing English words. In the semantically relevant acrostic acronyms, their meaning can be related to the message of the source phrase. However, the irrelevant acrostic cannot, despite their suggestive meaning. Table 11 shows 6 relevant and 13 irrelevant acrostic acronyms found in contrast with the 31 non-acrostic acronyms. This indicates that composing homophonous acronyms is more difficult than composing non-acrostic ones. Moreover, composing semantically relevant acrostic is more difficult than composing irrelevant ones. Among the 19 acrostics, six of them are semantically related to the message conveyed by the source phrase of the acronyms. This indicates that the acronym makers of these relevant acrostics worked harder, making sure the acronyms represent the events. The following data confirmed what Kreidler [2000] and Makkai [1974] had predicted that the coiners would select letters to result in not only pronounceable but also euphonious and meaningful acronyms.

Table 11. Semantic value of the acronyms

\begin{tabular}{|l|l|l|l|}
\hline No. & Types of Acronyms Process Formation & Frequency & Percentage \\
\hline $\mathbf{1}$ & Semantically relevant acrostic & 6 & 12 \\
\hline $\mathbf{2}$ & Semantically irrelevant acrostic & 13 & 26 \\
\hline 3 & Non-acrostic acronyms & 31 & 62 \\
\hline Total & 50 & 100 \\
\hline
\end{tabular}

Table 12. Semantically relevant/irrelevant acrostics

\begin{tabular}{|c|c|c|}
\hline No. & Relevant (a) & Irrelevant (b) \\
\hline 1 & $\begin{array}{l}\text { AMFETAMIN (Airlangga Farmasi on } \\
\text { Essay Islamic Competition) }\end{array}$ & ARISE (Administration Impacts Society) \\
\hline 2 & BEE (Biology Education Expo) & $\begin{array}{lll}\text { BEASt (Business } & \text { Entrepreneurship } & \text { (and) } \\
\text { Advertising Strategy) } & \end{array}$ \\
\hline 3 & $\begin{array}{l}\text { INOVASI (Indonesian Youth Festival of } \\
\text { Science) }\end{array}$ & $\begin{array}{l}\text { CHEEPS (Chemical Engineering Paper } \\
\text { Competition) }\end{array}$ \\
\hline 4 & NASA (National Scientific Days) & $\begin{array}{l}\text { DEFINE (Diponegoro Financial National } \\
\text { Competition) }\end{array}$ \\
\hline 5 & $\begin{array}{l}\text { REACTION (Research of Applied } \\
\text { Chemistry Competition) }\end{array}$ & EPIC (Economic Paper of Indonesian Condition) \\
\hline 6 & $\begin{array}{l}\text { TENSES (Teenager English Competition } \\
\text { in SMANsasi) }\end{array}$ & $\begin{array}{l}\text { GRAVITATION (The Greatest Victory Celebration } \\
\text { of Communication) }\end{array}$ \\
\hline
\end{tabular}




\begin{tabular}{|l|l|l|}
\hline 7 & & $\begin{array}{l}\text { MANIAC (Multimedia and Interactive Art } \\
\text { Competition) }\end{array}$ \\
\hline 8 & & SPACE (Sharia Paper Competition) \\
\hline 9 & & NEO (National English Olympiad) \\
\hline 10 & & $\begin{array}{l}\text { SEVENTSEAS (Sharia Economics Event South East } \\
\text { Asia) }\end{array}$ \\
\hline 12 & & INJECTION (Science Project Competition) \\
\hline 13 & & $\begin{array}{l}\text { COSMIC (Carnival of Sensation Music } \\
\text { Cooperative) }\end{array}$ \\
\hline
\end{tabular}

67 Some acronyms can be related to the meaning of the source phrase: for example, AMFETAMIN (12.1a) is related to something pharmaceutical/pharmacology; in biology people may discuss a BEE (12.2a); similarly, in English, we discuss TENSES (12.6a); and also people talk about a REACTION (12.5a) in chemistry. The acronym NASA (12.4a) in this research is undoubtedly a reinterpretation of the American NASA, National Aeronautics and Space Administration. The Indonesian NASA is an example of a semantically relevant acrostic because it involves something scientific, just as the original NASA does. This evidence shows that the coiner creates a homophonous acronym by reinterpreting an existing acronym. In Indonesia, NATO, not found in the research, is also popularly understood as no action talk only. It takes both creative effort and a good grasp of the English source phrase to create semantically relevant acrostics and convey the event's message in the acronym. On the other hand, the coiners create an acronym, the name of an event, and then construct the acronym expansion.

The irrelevant acrostics do not seem to intentionally convey the message of the source phrase, despite their suggestive meaning, but rather they appear to convey meaning through the names. For example, the acronym BEASt (12.2b) could convey the aggressive strategies the participants may learn for their business. Although the message conveyed from the source phrase is not very clear, GRAVITATION (12.6b) metaphorically could mean that the feeling the winners get in a celebration party after winning a competition is like those heavenly bodies attracted to gravitation. MANIAC (12.7b) and EPIC (12.5b) may suggest enthusiasm, and COSMIC (12.12b), SEVENTSEAS (12.10b) and SPACE (12.8b) may suggest vastness. However, they do not convey the meaning of their sources.

From both acrostics sub-categories, it is clear that their formations are not dependent on their structural categories. Either acrostic acronym can be elliptic or non-elliptic, and initials non-initial can be employed. Suggestive acrostic acronyms allow the readers/audience to relate the acronym to a particular message. This illustrates how the acronym makers make the best out of the sources to create meaningful acrostic acronyms. Those non-acrostic acronyms, with suffix ending -tion, are expected to relay the message of the coiners to the public the English values of the acronyms: academic, educated, and exclusive. 


\section{Conclusion}

The following summarizes the extent to which the acronyms makers follow the English acronyms rules. Tables 2 and 3 show that equally, they can create non-elliptic and elliptic acronyms. When they do the former, one-third compose their acronyms only using initials retained from all source words. The rest use the combination of initial, medial, and final letters. When creating elliptic acronyms, most of them sacrifice most function words and a few content words.

71 From the shortening process and grapheme order, the acronym makers tend to take the liberty of employing more Indonesian shortening rules. Although the acronym makers adopt English rules such as retaining initial letters of the source word, they also retain the medial and final letters. The length of the letters retained up to 5 letters speak. Moreover, they do not extend the initial with the next letter. However, they also retain splinters, for example, jec from project, am from Islamic and tal from digital, and syllables, for example, bot from robot, tion from, among others, competition, and speak.

The interesting finding of the extended retained parts in this research shows that the component letters are separated by some letters. There are 2-letter separated; for example, in this word, the underlined words are the retained parts: $\underline{\text { music }}$ in COSMIC; 4 letters away, exhibition in NEXT; and six letters away solutions in ECSOS. These findings are common in Indonesian acronym formations, as shown by Soeparno's patterns 7 and 8.

73 Although an inversion strategy is not available in the Indonesian acronym rules, five acronyms are coined using this strategy. Like the extended retained part, the inverted order of the letters is not always between two immediate letters, such as at in celebration becomes ta in GRAVITATION. The research also shows the involvement of inversion from two words in the source phrase; for example, in NESCO, the letter $S$ comes from the initial of the last word in the source. The fact that the inversion rule does not exist in Indonesian acronym formation shows that the makers only rely on English rules. However, generally extra-grammatical English word formations are not inclusively taught in Indonesian classes. The coiner independently learns the rules from the English acronyms they encounter online or simply creatively uses the available rules in the source words to coin the acronyms.

74 Although the formula of recursive acronyms is mentioned in Mattiello [2013], such data are not found in this research; however, several multiple acronyms in which abbreviations are present in their source phrases do not coincide with the reflexes are found. Therefore, such a classification is included. As multiple acronyms are possible in Indonesian, the acronym coiners could have applied analogy in processing their acronyms. They may also use the internet as a reference because the similar formation is evident and easily accessed online. Thus, the internet could be an important way for them to learn English acronym rules.

Further study on English acronyms still needs to be done; at least, the formula proposed by Mattiello [2013] needs revision, especially with the growing use of multiple acronyms, even in the outer circles of scientific and computing fields. Moreover, other rules such as adopting the middle and final letter(s) in creating acronyms need to be reformulated as there is a growing tendency of people deriving acrostic acronyms 
semantically from the source phrases. The rules may also be applicable in creating an acronym whose source phrase is built later.

A more extensive study of English acronyms in the Indonesian context for other naming purposes also should be conducted to better understand the patterns of English acronyms in Indonesia. The implication of such study is important in the English learning contexts in Indonesia, where students need to acquire the prescribed and formal rules. The creative rules in constructing acronyms in the Inner and Outer circle communities can be accessed and learned thanks to the internet. In the same way, the Expanding Circle communities share their "English" to wider circles of the World Englishes index, again thanks to the internet. This study can be a starting point to determine the position of English in an Indonesian context and identify Indonesia's position in the World Englishes index, especially the position of Indonesian morphology of shortening cross-linguistically.

\section{BIBLIOGRAPHY}

ADAMS Valerie, 1973, An Introduction to Modern English Word-Formation, Longman.

ALASHQUER Rand, 2016, The Phonological Structure of Acronyms in English within the Framework of Markedness Theory, Al-Noor University College, https://www.researchgate.net/publication/ 349427700_THE_PHONOLOGICAL_STRUCTURE_OF_ACRONYMS_IN_ENGLISH_WITHIN_THE_FRAMEWORK_OF_MARKEDNESS_THEORY BERMAN Jonathan M, 1961, “Contribution on Blending”, Zeitschrift für Anglistik und Amerikanistik, Walter de Gruyter, 278-281.

CAHN Lauren, 2021, 50+ Acronym Examples and Texting Abbreviations, Reader's Digest: https:// www.rd.com/article/acronym-examples/

CALDERARO Adriana et al., 2015, "Matrix-Assisted Laser Desorption/Ionization Time-of-Flight (MALDI-TOF) Mass Spectrometry Applied to Virus Identification”, Scientific Reports 4(1), 6803.

CANAGARAJAH Suresh, 2006, "Changing Communicative Needs, Revised Assessment Objectives: Testing English as an International Language”, Language Assessment Quarterly 3(3), 229-242.

CANNON Garland, 1989, “Abbreviations and Acronyms in English Word-Formation”, American Speech 64(2), 99.

CHAER Abdul, 2008, Morfologi Bahasa Indonesia: Pendekatan Proses, Rineka Cipta.

CONTI Sara \& MATTIELlo Elisa, 2008, "Extra-Grammatical Morphology: English Acronyms and Initialisms", in PAPI Marcella Bertuccelli, BERTACCA Antonio \& BRUTI Silvia (Eds.), Threads in the Complex Fabric of Language: Linguistic and Literary Studies in Honour of Lavinia Merlini Barbaresi, Feliciti Editore, 559-573.

DE VRIES Jan Willem, 1970, "Indonesian Abbreviations and Acronyms", Bijdragen Tot de Taal-, LandEn Volkenkunde /Journal of the Humanities and Social Sciences of Southeast Asia 126(3), 338-346.

FANDRYCH Ingrid, 2008, "Submorphemic Elements in the Formation of Acronyms, Blends, and Clippings", Lexis 2. 
JACOBS Kayla, ITAI Alon \& WINTNER Shuly, 2020, “Acronyms: Identification, Expansion and Disambiguation”, Annals of Mathematics and Artificial Intelligence 88(5-6), 517-532.

JAKARTAPOST, 2010, “Acronyms”: https://www.thejakartapost.com/directory/acronyms JAMET Denis, 2009, “A Morphophonological Approach to Clipping in English”, Lexis HS 1.

KACHRU Braj B, 1986, The Alchemy of English: The Spread, Functions, and Models of Non-native Englishes, Pergamon.

KREIDLER Charles W, 1979, “Creating New Words by Shortening”, Journal of English Linguistics 13(1), 24-36.

KREIDLER Charles W, 2000, “Clipping and Acronymy”, in BOoIJ Geert Evert (Ed.), Morphology: An International Handbook on Inflection and Word Formation, Walter de Gruyter, 956-963.

KRIDALAKSANA Harimurti, 1989, Pembentukan Kata dalam Bahasa Indonesia, PT Gramedia.

LOPEZ RUA Paula, 2002, "On the Structure of Acronyms and Neighboring Categories: a PrototypeBased Account", English Language and Linguistics 6(1), 31-60.

MAKKAI Adam, 1974, "Acronymy in English: A Stratificational Re-examination", Proceedings of the Eleventh International Congress of Linguists, 345-363.

MATTIELlo Elisa, 2008, An Introduction to English Slang: A Description of Its Morphology, Semantics, and Sociology, Polimetrica, International Scientific Publisher.

MATTIELlo Elisa, 2012, “Abbreviations in English and Italian Scientific Discourse”, ESP Across Cultures IX, 149-168.

MATtiello Elisa, 2013, "Extra-Grammatical Morphology in English”, Word Structure Vol. 10, Issue 2, de Gruyter.

MOEHKARDI Rio Rini Diah, 2016, "Patterns and Meanings of English Words through Word Formation Processes of Acronyms, Clipping, Compound and Blending Found in Internet-Based Media", Humaniora 28, 324-338.

MoEliono Anton M., RIFAI Mien A., ZABADI Fairul \& Sugono Dendy, 2005, Pedoman Umum Pembentukan Istilah, Pusat Bahasa, Departemen Pendidikan Nasional.

NIKAFROOZ Mohammad, veYSI Elkhas \& PAZHAKH Abdolreza, 2014, "Generative Aspects of Acronyms", International Journal of Language Learning and Applied Linguistics World, 245-258: https://www.researchgate.net/publication/314095289_GENERATIVE_ASPECTS_OF_ACRONYMS NOTOSUSANTO Nugroho, 1979, "Masalah Akronim dan Singkatan dalam Perkembangan Bahasa Indonesia", Bahasa Dan Sastra, 2-10.

PETERSON Lucas Kwan, 2019, “The Official Instant Ramen Power Rankings”, Los Angeles Times: https://www.latimes.com/food/story/2019-11-05/instant-ramen-power-rankings-lucaspeterson

PLAG Ingo, 2003, Word-Formation in English, Cambridge University Press.

QUIRK Randolph, LEECH Geoffrey \& GREENBAUM Sidney, 1985, A Comprehensive Grammar of the English Language, Longman.

Wikipedia, 2021, "Recursive acronym": https://en.wikipedia.org/wiki/Recursive_acronym

Word Spy, 1997, “Recursive acronym”: https://wordspy.com/index.php?word=recursive-acronym 
RENNER Vincent, 2018, "Structural Borrowing in Word-Formation: An Exploratory Overview", SKASE Journal of Theoretical Linguistics 15(2), 2-12.

SOEPARNO, 1985, “Akronim dan Masalahnya (Acronym and Its Problems)”, Bahasa Dan Sastra, 9-17.

SOUDEK L. J, 1978, “The Relation of Blending to English Word-Formation: Theory, Structure, and Typological Attempts", in DRESSLER Wolfgang U. \& MEID Wolfgang (Eds.), Proceedings of the Twelfth International Congress of Linguists, Institut für Sprachwissenschaft der Universität Innsbruck, 462-466.

STOCKWELl Robert \& MINKOVA Donka, 2001, “Word-origins”, English Words, Cambridge University Press, 5-23.

THOMASON Sarah, 2001, Language Contact: An Introduction, Edinburgh University Press.

THOMASON Sarah, 2010, “Contact Explanations in Linguistics”, The Handbook of Language Contact, Wiley-Blackwell, 29-47.

UNGERER Friedrich, 1991, “Acronyms, Trade Names and Motivation”, AAA: Arbeiten Aus Anglistik

Und Amerikanistik 16(2), 131-158: https://www.jstor.org/stable/43023574

WEINREICH Uriel, 1979, Language in Contact, de Gruyter.

WILCOX Allen J. \& MCCANN Margaret F., 2009, “Editors Declare a BAN (“Banish Acronyms Now”)", Epidemiology 20(1), 2.

\section{ABSTRACTS}

This article investigates the formation of English acronyms used to name school events in an Indonesian setting. The data collected from Instagram and offline sources were taken from April to August 2018 and were classified and analyzed following Mattiello's [2013] and Soeparno's [1985] frameworks.

There were 29 non-elliptic acronyms and 21 elliptic acronyms, of which six content words are not represented in the acronym; yet, two function words are. This research found one acronym with a consonant addition, and 24 extended acronyms. The initials retained could be followed by a non-immediate letter. Five inverted acronyms were also found, one of which involved two letters from two source words. There were seven multiple acronyms in this current research, four of which include acronyms and three of initialisms in their sources. The study also found 19 acrostic acronyms, six of which were semantically relevant.

The research concludes that the English acronyms examined were also influenced by Indonesian acronym rules, especially at the length of the retained parts and the position of the retained parts in the source words. There is frequent use of non-initials and more letters retained from the source words in composing the acronyms.

Cet article présente l'enquête sur la formation des acronymes anglais utilisés dans le cadre d'événements scolaires en contexte indonésien. Les données recueillies sur Instagram et via des sources hors ligne s'étendent d'avril à août 2018 et ont été classées et analysées en suivant les cadres de Mattiello [2013] et de Soeparno [1985].

Elles comprennent 29 acronymes non elliptiques et 21 acronymes elliptiques, parmi lesquels six mots à contenu lexical non représentés dans l'acronyme ; pourtant, deux mots à fonctionnement grammatical le sont. Cette recherche a dégagé un acronyme avec ajout de consonnes et 24 acronymes étendus. Les acronymes retenus pouvaient être suivis d'une lettre non immédiate. 5 acronymes inversés ont également été trouvés, dont l'un impliquait deux lettres de deux mots 
sources. Sept acronymes multiples ont été relevés dans cette recherche, dont 4 comprennent des sigles et 3 des initiales dans leurs sources. L'étude a également trouvé 19 acronymes acrostiches, dont 6 étaient sémantiquement pertinents.

La recherche conclut que les acronymes anglais examinés sont également influencés par les règles de l'acronyme indonésien, notamment au niveau de la longueur des segments retenus et de la position de ces derniers dans les mots sources. On note une utilisation fréquente de noninitiales et une majorité de lettres retenues dans les mots sources pour la composition des acronymes.

INDEX

Mots-clés: acronymes anglais, contexte indonésien, noms d'événements, formation lexicale Keywords: English acronym, Indonesian context, names of events, word-formation

\section{AUTHOR}

\section{RIO RINI DIAH MOEHKARDI}

Universitas Gadjah Mada, Yogyakarta, Indonesia

riomoehkardi@ugm.ac.id 